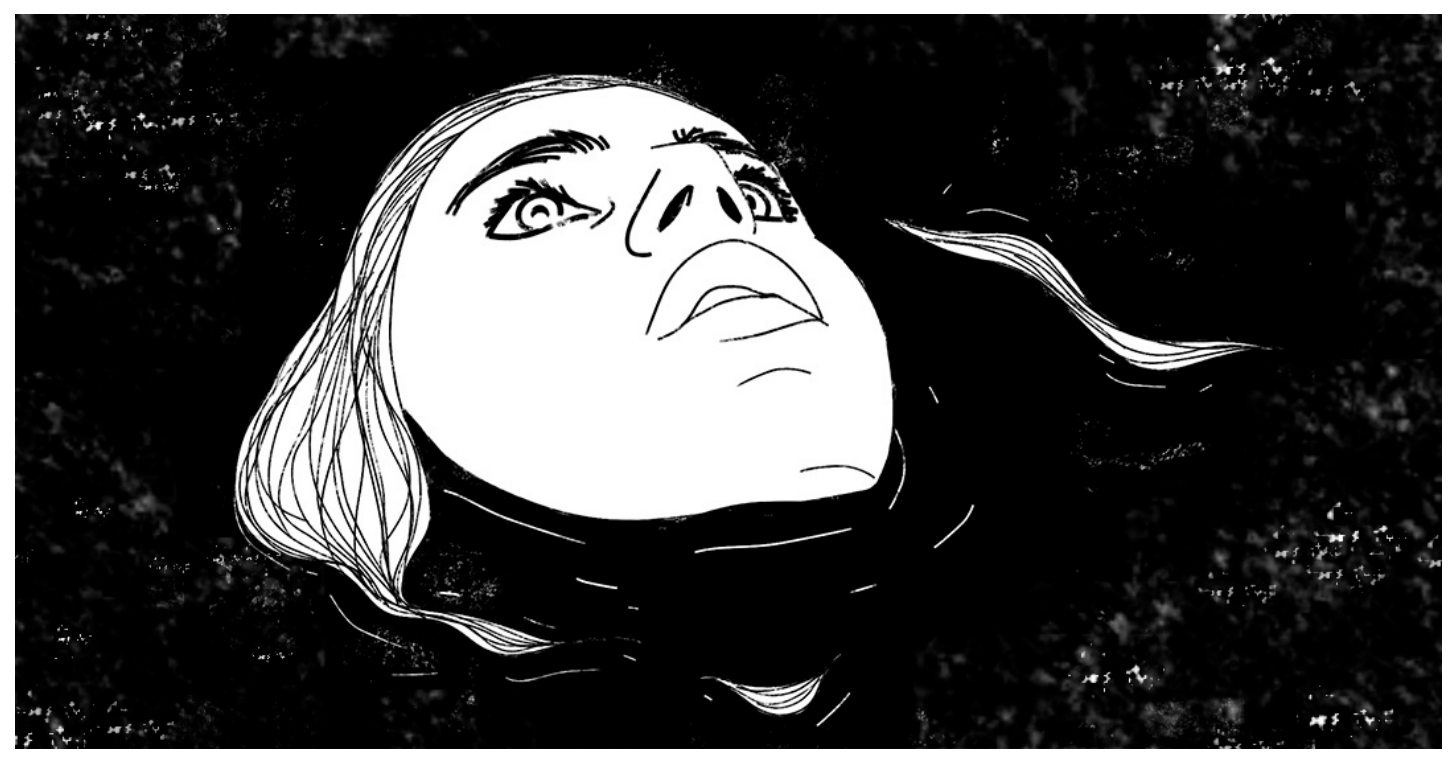

Artista invitada

Carmen Lehmann Ayerbe

Sumergirse o flotar

Dibujo digital

2020

Cortesía revista Ojo de Pez 


\title{
Definiciones del concepto de «religión» en el marco de las relaciones de poder modernas*
}

\author{
Jean Paul Sarrazin (Colombia)**
}

\section{Resumen}

En este artículo se examinan las implicaciones políticas de los usos y sentidos del concepto de «religión» manifiestos en medios académicos e institucionales. Para ello se presenta una revisión de algunas de las principales definiciones del concepto provistas por las ciencias sociales, las cuales son analizadas críticamente y teniendo en cuenta sus consecuencias en el contexto moderno de relaciones de poder. La investigación identifica cinco tipos de presupuestos presentes en estas definiciones: a) la religión se concibe por oposición a la secularidad, b) se la imagina bajo una forma institucionalizada, c) que se expresa como un conjunto de creencias, d) las cuales son un asunto privado y e) que tienen por objeto seres o fuerzas sobrenaturales. Se concluye que lo que hoy se entiende por «religión» no puede desligarse de procesos de legitimación y de dominación, y que utilizar el término

[ 72 ] para clasificar ciertas expresiones culturales puede opacar sus particularidades y excluirlas del debate público.

\section{Palabras clave}

Religión; Secularidad; Creencias; Legitimación; Pluralismo; Modernidad.

Fecha de recepción: julio de 2020

- $\quad$ Fecha de aprobación: noviembre de 2020

\section{Cómo citar este artículo}

Sarrazin, Jean Paul. (2021). Definiciones del concepto de «religión» en el marco de las relaciones de poder modernas. Estudios Políticos (Universidad de Antioquia), 60, pp. 72-93. DOI: 10.17533/udea.espo.n60a04

\footnotetext{
* Este artículo de revisión se deriva del proyecto de investigación Religión y pluralismo, realizado de manera independiente y sin financiación institucional específica.

** Antropólogo. Magíster en Migraciones y Relaciones Interétnicas. Doctor en Sociología. Facultad de Ciencias Sociales y Humanas, Departamento de Sociología, Universidad de Antioquia UdeA. Calle 70 No. 52-21, Medellín, Colombia. Correo electrónico: jean.sarrazin@udea.edu.co - Orcid: 0000-0002-8022-4674 - Google Scholar: https://scholar.google.com/citations?view_op=list_ works\&hl=es\&user=7kh5_1QAAAAJ
} 


\title{
Definitions of the Concept of «Religion» in the Context of Modern Power Relations
}

\begin{abstract}
This article examines political implications of the uses and meanings of the concept of «religion» in academic and institutional contexts. It presents a review of some of the main definitions of the concept provided by the social sciences, which are critically analyzed considering their consequences in the modern context of power relations. The investigation identifies five types of assumptions present in these definitions: a) Religion is conceived as opposed to secularity, c) it is imagined under an institutionalized form, b) it is expressed as a set of beliefs, d) which are considered as a private matter, and e) are about supernatural beings or forces. It is concluded that what we understand today as «religion» cannot be separated from processes of legitimation and domination, and that using the term to classify certain cultural expressions may overshadow their particularities and exclude them from public debate.
\end{abstract}

\section{Keywords}

Religion; Secularity; Beliefs; Legitimation; Pluralism; Modernity. 


\section{Introducción}

A pesar de vivir en una «era secular» (Taylor, 2007), la creciente importancia de lo religioso en el ámbito público ha llevado a plantear conceptos como la «des-secularización» del mundo (Berger, 1999) o la «post-secularidad» (Habermas, 2010). En América Latina, la disminución de adeptos al catolicismo ocurre al mismo tiempo que aumenta la visibilidad de la diversidad religiosa (Bastian, 2007; Beltrán, 2013; Parker, 2005). Por otro lado, muchos países como Colombia han optado por un modelo político pluralista que busca reconocer e incluir aquella diversidad en sus territorios. Este proceso ha dado lugar a múltiples debates sobre los alcances del pluralismo en materia religiosa y a una pregunta fundamental: ¿qué tipo de grupos y expresiones culturales se deben considerar como «religiosos»? Para contestar esa pregunta es necesario definir previamente los criterios según los cuales se identifica lo religioso, lo cual no es otra cosa que definir la categoría de «religión».

A menudo se ha dado por sentado que la religión es un hecho cuya existencia resulta evidente y claramente identificable; sin embargo, como se muestra en este artículo, la verdad es que la determinación de lo que puede

[ 74 ] o debe ser considerado como religioso en la infinita gama de fenómenos culturales, al igual que la definición de los elementos que distinguirían lo religioso, es un asunto complejo, polémico y profundamente político.

La definición de religión ha sido largamente debatida en las ciencias sociales. Desde diferentes perspectivas teóricas — como las sustantivistas (Otto, 2005) o las funcionalistas (Durkheim, 1982) — se han propuesto comprensiones contrastadas respecto a lo que el término denota y connota, así como las maneras en que debe ser utilizado, tanto por la academia como por el Estado. Una revisión de la literatura en ciencias sociales muestra que, lejos de existir una esencia religiosa universalmente identificable, el concepto de religión es un constructo cultural particular de Occidente (Beckford, 2003; Beaman, 2013), con unos fundamentos históricos e ideológicos (Fitzgerald, 2007; Masuzawa, 2005; Nongbri, 2013).

El término viene directamente del latín religio, pero desde la Roma antigua la utilización de la categoría fue un terreno en disputa, ya que solo se utilizaba para categorizar ciertas celebraciones públicas reconocidas por los gobernantes; en ese contexto, el cristianismo logró finalmente ser considerado 
como religio luego de un proceso complejo y evidentemente político (Debray, 2005). En la Edad Media la categoría también estuvo relacionada con el reconocimiento oficial y se entendía por oposición al paganismo y la superstición (Smith, 1998). Asimismo, lo que hoy se entiende por «religión» no puede desligarse de procesos de legitimación y de dominación.

La distinción entre lo religioso y lo secular es producto del pensamiento moderno (Latour, 2013). La naturaleza compleja de la religión implica que, en ciertas circunstancias, sus límites se desdibujan. Así, se puede encontrar elementos religiosos en ámbitos supuestamente seculares y es necesario problematizar el acto de clasificar como religiosas ciertas expresiones culturales o determinadas formas de vivir y entender el mundo. En su contundente crítica contra las principales teorías clásicas referentes a las llamadas «religiones primitivas», Edward Evans-Pritchard (1973) plantea que autores fundantes de las ciencias sociales del siglo xIX, como James Frazer, Herbert Spencer o Edward Tylor, transfirieron a sus escritos una serie de prejuicios etnocéntricos acerca de la religión en Occidente. En línea con lo anterior, Peter Berger (1974, p. 128) sostiene que las más influyentes definiciones del concepto de religión han obstaculizado el conocimiento sobre las particularidades y la coherencia de otros sistemas culturales.

El objetivo de este artículo es analizar los diferentes presupuestos sobre los cuales se han basado las definiciones modernas de religión y los efectos políticos de ello. No se trata de establecer cuál de ellas sería la más apropiada, sino de examinar sus componentes e implicaciones. En este recorrido se consideran cinco tipos de presupuestos: a) la religión por oposición a la secularidad; b) las religiones como Iglesias; c) la religión como un conjunto de creencias; d) la religión como un asunto privado o personal; e) la religión como creencias en seres o fuerzas sobrenaturales. Previamente a este recorrido, se presentan algunas definiciones de religión emitidas desde la institucionalidad. Estos ejemplos permiten observar los términos allí utilizados y algunas de las problemáticas que se han suscitado.

Se empleó una metodología cualitativa, específicamente el análisis hermenéutico y argumentativo de las diferentes definiciones de religión que sobresalen en las ciencias sociales y que han tenido relevancia e incidencia en las maneras de concebir dicho concepto por parte de entes de poder en la esfera pública e instituciones oficiales del Estado. En estos textos se identificaron los presupuestos y las estructuras conceptuales que sustentan las diferentes 
definiciones, así como sus consecuencias lógicas y prácticas en algunos casos concretos de la realidad social. Aquellas definiciones no siempre se plantean en la literatura o en los textos oficiales de manera explícita, por lo que también se analizaron las formas en que dichos textos clasifican lo que es considerado como «religioso» y las características que se atribuyen a ello. Aunque el tema de la relación entre religión y política ha sido ampliamente trabajado en las ciencias sociales, la pesquisa se centró en examinar específicamente aquellas obras de relevancia académica en las que se proporciona una definición del concepto de religión o donde se caracteriza lo religioso — por oposición a lo que no lo es-. Estas definiciones y caracterizaciones fueron luego clasificadas de acuerdo con sus componentes $y$, gracias a lo anterior, se identificaron los cinco tipos de presupuestos mencionados anteriormente.

\section{Algunas definiciones y problemáticas institucionales. A modo de ilustración}

El Artículo 18 de la Constitución Política de Colombia establece que «Se garantiza la libertad de conciencia. Nadie será molestado por razón de sus convicciones o creencias ni compelido a revelarlas ni obligado a actuar contra su conciencia». El Artículo 19, por su parte, afirma que «Se garantiza

[ 76 ] la libertad de cultos. Toda persona tiene derecho a profesar libremente su religión y a difundirla en forma individual o colectiva. Todas las confesiones religiosas e iglesias son igualmente libres ante la ley». Estos son los artículos más relacionados con la religión o la libertad religiosa de la Constitución colombiana, pero en ellos no se define el concepto de «religión». El vacío conceptual viene a subsanarse pocos años más tarde en la Sentencia C-088 de 1994 de la Corte Constitucional. Allí se declara que «el sentido general de la palabra religión, es el que comprende el conjunto de creencias o dogmas acerca de la divinidad, de sentimientos de veneración y de temor hacia ella, de normas morales para la conducta individual y social y de prácticas rituales, principalmente de oración y el sacrificio para el culto». Tanto en los artículos de la Constitución, como en la sentencia mencionada, se observan palabras clave que se analizarán más adelante, tales como «creencias», «lglesias»o «divinidad». ¿Se debe entender a las religiones como conjuntos de creencias? ¿Son las religiones «lglesias»?

La Sentencia C-088 de 1994 realiza una revisión del proyecto de la Ley Estatutaria 133 de 1994 sobre el derecho a la libertad religiosa y de cultos, en cuanto a su constitucionalidad. Dicha Ley, al ser promulgada, aclara que 
no incluye actividades «relacionadas con el estudio y experimentación de los fenómenos psíquicos o parapsicológicos; el satanismo, las prácticas mágicas o supersticiosas o espiritistas u otras análogas ajenas a la religión», ya que estas «no alcanzan a constituir lo que la experiencia destaca como religión, ni como confesión religiosa». Se evidencia así que, de acuerdo con la institucionalidad colombiana, la «religión» tiene unas particularidades que permiten identificar, incluir y excluir ciertas creencias, prácticas y agrupaciones.

Según la Sentencia T-662 de 1999, «la doctrina constitucional ha precisado que la religión consiste en una relación personal con Dios, la cual se expresa exteriormente a través del culto público o privado; el culto, por su parte, debe ser entendido como el conjunto de demostraciones exteriores presentadas a Dios. Por este motivo, sin la relación con Dios, esto es sin religión, no se da un culto». Se observa aquí que la relación personal con Dios es equiparada a la religión, lo cual suscita nuevas preguntas: ¿qué significa que esta relación sea «personal»? Y, por otro lado, ¿tienen todas las religiones una «divinidad»? ¿Es la «divinidad» un ser sobrenatural?

En lo que respecta al acto de clasificar una práctica o un grupo como «religiosos», las consecuencias son considerables. En algunos casos, lo que se considera bajo esa categoría se excluye de la esfera de lo púbico y así se restringe su poder. El laicismo francés llega al punto de no aceptar la utilización del hijab — velo, en lengua árabe- en los colegios públicos, ya que Francia rechaza cualquier símbolo religioso en instituciones estatales; sin embargo, hay quienes pueden argumentar que el hijab no es un símbolo religioso sino parte de una tradición cultural, argumento que impediría al Estado francés prohibir esa prenda de vestir y permitiría a otros grupos, como los Sikhs, utilizar igualmente su turbante en establecimientos públicos (Beaman, 2013).

En otros casos, particularmente en los Estados pluralistas, lo religioso es objeto de una forma de discriminación positiva que concede libertad de culto y ciertos privilegios a las organizaciones religiosas. En Reino Unido, de acuerdo con una cierta definición de religión, los adeptos a la cienciología lucharon para que esta fuera declarada como religión por la Corte Suprema de Justicia Británica en 2013 (Judgment UKSC 77). En Colombia, los grupos religiosos pueden beneficiarse de la reducción del impuesto predial de sus lugares de culto; sin embargo, hay casos en que las políticas pluralistas también tienen efectos inesperados. Por ejemplo, la Corte Constitucional de Colombia, en la Sentencia SU-510 de 1998, adjudicó la categoría de «comunidad religiosa» a 
una etnia indígena — los arhuaco o ijka-. Esta clasificación, aunque buscaba proteger la integridad cultural de la etnia, tuvo como consecuencia que la Corte no tutelara el derecho a la libertad religiosa de un grupo minoritario de indígenas evangélicos que viven en el resguardo arhuaco (Sarrazin y Redondo, 2018). Se observa que, aun si se trata del Estado pluralista que dice reconocer la diversidad religiosa, la categoría de «religión» puede utilizarse de una manera tal que sus efectos son susceptibles de afectar negativamente ciertas expresiones religiosas minoritarias.

\section{Religión por oposición a la secularidad}

En la modernidad, la religión se concibe por oposición al de secularidad; sin embargo, la división tajante que la modernidad plantea entre la «esfera religiosa» y las demás esferas, Ilamadas «seculares» — notablemente la política y la economía-, es una división inexistente en el pensamiento de sociedades no modernas. En la Edad Media, la misma Iglesia utiliza la categoría de lo «secular», pero el término no se entendía por oposición a lo religioso en general, sino que designaba simplemente los objetos, prácticas o personas que no pertenecían a la Iglesia (Casanova, 1994, pp. 14-15). Por otro lado, desde la alta Edad Media la Iglesia se autoproclamó como la Religión y predominaba

[ 78 ] sobre todos los ámbitos de la vida social (Beyer, 1999, pp. 205-206). No existían entonces una política o una economía seculares.

Siglos más tarde, la modernidad utiliza la misma palabra y la convierte en una categoría epistémica fundamental en su proyecto transformador del sistema político (Casanova, 2009), un proyecto que implica despojar a la institución eclesial del inmenso poder que ostentaba en la Edad Media. Aunque el discurso moderno y secularista plantea que la religión debe separarse y no interferir en las otras esferas de la sociedad, en realidad se trata de la separación de la religión institucionalizada, representada prototípicamente por la Iglesia. ${ }^{1}$

Vivir en una «era secular» significa que las esferas seculares han de tener mayor peso y legitimidad en el espacio público (Taylor, 2007). Es entonces la modernidad liberal, fruto de las revoluciones burguesas, la que ha instaurado aquella dicotomía religiosidad-secularidad, principio clasificatorio conducente a impedir que la Iglesia y las demás instituciones religiosas accedan al poder estatal (Asad, 1993, p. 28). Ello se justifica, en parte, mediante el discurso

${ }^{1}$ Esta asociación religión-Iglesia es un tema clave que se abordará en el siguiente apartado. 
según el cual la secularidad estaría regida por la objetividad y la racionalidad, mientras que la religión corresponde a un estado primitivo de irracionalidad que no tiene cabida en los debates sobre lo público. Este secularismo se manifiesta en algunas versiones del liberalismo y del laicismo republicano (Bobbio, 2005; Mardones, 2006).

A pesar de que recientemente se evidencie una mayor visibilidad de algunas religiones en la esfera pública (Casanova, 1994; Habermas, 2006), desde la llustración se concibió a un hombre moderno emancipado de la religión, un proyecto que, además, se expandió a escala global a través de la colonización y la modernización en países como Colombia. Se ha reproducido un mito moderno en el cual la humanidad avanza de la «oscuridad» de una Edad Media — regida, recuérdese, por la Iglesia— hacia la luz pura de la Razón (Casanova, 2009, p. 1054). Esto reafirmó, evidentemente, la idea de que la religión es inferior a la secularidad y que esta división no es la construcción sociocultural de un momento histórico que se da en medio de luchas por el poder, sino la expresión del ineluctable progreso de la humanidad. Se volvió «natural» que una persona ilustrada, moderna y liberal tenga un pensamiento secular, es decir, emancipado de cualquier religión (Casanova, 2009, p. 1055).

Si bien es evidente que la institución religiosa tradicional puede ser destruida o excluida de las decisiones que afectan la vida cotidiana, la separación tajante entre lo religioso y lo secular, en tanto que categorías analíticas, es una demarcación arbitraria dentro de los fenómenos culturales (Smith, 1982), un acto de clasificación que surge en el marco de relaciones de poder (Arnal y McCutcheon, 2013). Por eso, autores como Jacques Derrida (1996), Ninian Smart (2005) o Peter Beyer (2013), entre otros, han demostrado que es analíticamente inviable trazar los límites precisos que separarían lo religioso de lo político, lo legal, lo económico, entre otros.

Por demás, esta separación se problematiza cuando se tiene en cuenta el grado en el que las formaciones modernas y seculares están permeadas por elementos comúnmente asociados a la religión como la sacralidad, la trascendencia, los valores supremos o el pensamiento mágico (Sarrazin, 2018). Émile Durkheim (1898, pp. 17-18), por ejemplo, consideró que las naciones modernas se basan en la sacralización de ideas como la patria, el progreso o la igualdad. Carl Schmitt (2000) mostró la importancia que ha tenido la teología en la conformación de los conceptos jurídico-políticos de los Estados modernos. Jonathan Benthall (2008), por su parte, observa que el 
comunismo o el nazismo toman el lugar de las religiones en una era secular. Por último, Robert Bellah (1967) ha demostrado la presencia de lo religioso en los principios republicanos y en los modelos de sociedad propuestos por el Estado liberal moderno, lo cual conformaría una «religión civil». Todo esto lleva a cuestionar la tradicional concepción de la religión como una esfera claramente separada y permite cuestionar si ha existido alguna vez una esfera completamente secularizada.

\section{Religiones como Iglesias}

Como expuso en el apartado anterior, desde la Edad Media se asoció la religión a la Iglesia, asociación que se transfirió a las ciencias sociales. Durkheim, considerado «padre de la sociología», planteó una definición funcionalista de religión que ha influenciado considerablemente el pensamiento académico y oficial. Según el célebre sociólogo, la religión es «un sistema solidario de creencias y de prácticas relativas a las cosas sagradas, es decir separadas, interdictas, creencias y prácticas que unen en una misma comunidad moral, Ilamada Iglesia, a todos aquellos que se adhieren a ellas» (Durkheim, 1982, p. 42). Esta visión ha sido considerada como «eclesiocéntrica» (Parker, 2010), ya que equipara la religión a la Iglesia —ecclesia—. Aunque evidentemente

[ 80 ] Durkheim nunca pretendió que la única religión fuera la institución cristiana, sí se trata de una perspectiva centrada en las instituciones religiosas que siguen patrones estructurales similares a las Iglesias.

El problema principal de esta definición de religión radica en que las expresiones religiosas del mundo no necesariamente corresponden al modelo eclesial, ni están institucionalizadas. Por otro lado, la asociación religiónIglesia ha permitido suponer que los sujetos religiosos necesariamente han perdido su agencia, ya que pertenecen a estructuras jerarquizadas donde se restringe la libertad individual. Así, la religión se identifica con un estado de sujeción — como se imagina al sujeto medieval—, estado que debería ser trascendido — gracias a la modernidad liberal— «a otro posterior de libertad» (Godoy, 2016).

Un eminente crítico de la visión eclesiocéntrica fue Thomas Luckmann (1973), que insiste en el error que han cometido las ciencias sociales al no «ver» aquellas expresiones no institucionalizadas. Según el autor, la «religión orientada hacia la Iglesia» es solo una de las formas que toma lo religioso: «el cosmos sagrado penetra la realidad social objetiva sin que para ello se requiera de una base institucionalizada distinta y especializada» (p. 72). Ampliar el 
espectro de lo religioso más allá de las instituciones también lleva a considerar que los sujetos religiosos no necesariamente pueden ser identificados de acuerdo con preguntas como «i̇a qué religión pertenece?». Existe un «creer sin pertenecer» (Davie, 1990) o un creer desinstitucionalizado que debe ser reconocido por parte de los Estados pluralistas.

Es así como, en el mundo actual, y particularmente en América Latina, los sujetos construyen religiosidades populares que no obedecen a los cánones de autoridades religiosas establecidas (Parker, 2005). Desde México (De La Torre, 2012) hasta Argentina (Mallimaci y Esquivel, 2014) se observa una cantidad cada vez más considerable de personas que «creen a su manera», es decir, que no recurren a las mediaciones institucionalizadas, ni se adscriben a una Iglesia u organización religiosa específica.

\section{Religiones como sistemas de creencias}

A medida que la modernidad se desarrolló, se reforzó la idea de que la religión era un conjunto de creencias, entendidas como estados mentales que pueden ser, de alguna forma, verbalizados a través del lenguaje. Esta concepción «intelectualizada» de la religión es un producto de la Reforma Protestante y su reacción contra del catolicismo medieval, con sus símbolos, sus rituales fastuosos y sus adoraciones cargadas de emotividad (Meyer, 2015). Jonathan Smith (1982) hace notar que hacia la mitad del siglo XVIII términos como «reverencia» o «adoración» fueron desligados de su connotación ritual, es decir, de una práctica social, y se les empezó a considerar como un estado de la mente. El autor Ilama a este proceso el «cambio hacia la creencia» shift to belief-, el cual se manifiesta en el racionalismo del siglo xVIII y su Ilustración (Smith, 1998, p. 272). En el momento en que las religiones son vistas como conjuntos de creencias surge, asimismo, una serie de preguntas críticas acerca de su credibilidad y, por tanto, de su veracidad (p. 271), lo que las opone a la ciencia y las deja en una posición de inferioridad respecto a esta última. En torno a la Razón de la Ilustración, señala Bruno Latour (2013), hubo una extraña amalgama entre conocimiento y religión, lo que lanzó a los modernos hacia una gran limpieza de «creencias falsas». Es el momento en que la religión deviene «creencia en algo» (p. 309). Por ambición, afirma el autor, la Iglesia sucumbe a la tentación de poder seguir dominando como lo hacía antes sobre todos los modos de pensamiento y quiso responder a sus contradictores en un lenguaje moderno. La religión se presenta entonces como un conjunto de afirmaciones que serían validables o falseables según 
los criterios del método científico, razón por la cual generalmente aparecen como errores del pensamiento que deberían suprimirse.

Lo anterior se trasladó a las descripciones que los modernos han hecho de las expresiones culturales del mundo entero, lo cual es una manifestación de etnocentrismo y colonialismo conceptual (Asad, 1993). Según Latour (2005), un gran error del pensamiento científico moderno es creer que los religiosos creen, es decir, transferir a los religiosos nuestras nociones de «creencia». Incluso los misioneros católicos notaron, desde hace siglos, que las personas de otros pueblos no necesariamente creen en algo o que puede ser imposible traducir a lenguas no europeas el concepto de «creer en Dios», por ejemplo (Asad, 1993, p. 40).

Más allá de una cuestión cognitiva, lo religioso puede entenderse como una manera de ser y de estar en el mundo. La religiosidad se viviría en la interacción con el mundo humano y no humano. Concebir las religiones como conjuntos de creencias deja de lado su aspecto emocional, ontológico, experiencial o el hecho de que la «religión» sería un «modo de existencia» (Latour, 2013) que implica motivaciones, horizontes de acción y disposiciones para la vida en sociedad.

\section{Las religiones como creencias personales}

Si la religión se concibe como un conjunto de creencias y estas yacen en las mentes de las personas, lo religioso se imagina en la interioridad del sujeto, es una experiencia que los individuos pueden vivir «en su soledad» (James, 1986, p. 18). Por ejemplo, el concepto latino de pietas —fundamental en la doctrina cristiana medieval - solo en la modernidad deviene en un sentimiento personal o en una disposición privada (Smith, 1982).

Esta forma de entender la religión tiene consecuencias sociopolíticas significativas. La religión como un asunto privado es una conceptualización fundamental para el establecimiento del Estado secular, ya que favorece la expulsión de la religión de la esfera pública. En el Estado secular y pluralista se tolera la diversidad religiosa gracias a que las religiones no interferirían en lo político. «El principio de separación entre la Iglesia y el Estado garantiza la libertad de creencia y congregación religiosa, pero al mismo tiempo claramente separa la esfera religiosa — que es considerada como esencialmente privadade la esfera política» (Bellah, 1967, p. 3. Traducción propia). Si la religión es un asunto privado, entonces no debería tener ningún protagonismo político. 
En Colombia, por tomar el ejemplo local, la libertad de cultos se manifiesta como una libertad individual; además de que «la doctrina constitucional ha precisado que la religión consiste en una relación personal con Dios» (Sentencia T-662 de 1999. Énfasis añadido). Desde el modelo liberal se plantea que los individuos son libres de profesar las creencias que deseen, pero que estas, justamente por ser privadas, no deben trascender a lo público. La posibilidad de concebir la religión como una cuestión privada, de creencias internas o de fe íntima, permite que en Francia — por tomar otro ejemplo- no esté prohibido ser musulmán, ya que semejante prohibición violaría el principio de libertad de pensamiento, caro al liberalismo, pero que se le prohíba a las musulmanas actuar acorde a su religión usando el velo o hijab. Sin embargo, una musulmana no puede serlo si no se le permite cambiar sus comportamientos, los cuales obviamente se manifiestan también en el espacio público (Sarrazin y Rincón, 2015). De igual manera, los cristianos insisten en que lo de ellos no es una religión, sino más bien un estilo de vida, argumentando que el comportamiento de las personas debe cambiar en todas las facetas de su vida en sociedad (Sarrazin y Arango, 2017).

Así como la división entre lo secular y lo religioso es analíticamente problemática, la separación entre lo público y lo privado también ha sido problematizada (Beckford, 2003). Contrariamente a la tesis de secularización que imaginaba la privatización total de lo religioso (Luckmann, 1973), José Casanova (1994) ha hecho notar que existen suficientes evidencias sobre la «des-privatización» de la religión, es decir, la aparición de varias tradiciones religiosas que se rehúsan a aceptar el lugar marginal y privado que el secularismo les ha querido asignar, reclamando un lugar y un papel activo en la esfera pública. Reconociendo la fuerza que pueden tener las religiones en los debates políticos, Jürgen Habermas (2005, p. 26) propone el concepto de «post-secularidad». Esto no significaría volver a regímenes teocráticos ni a Estados clericales, sino otorgar un lugar equitativo a las distintas expresiones religiosas en las discusiones democráticas.

Como ya se expuso, las religiones trascienden la esfera de lo privado hacia ámbitos públicos como la política o la economía. Ni siquiera en las sociedades modernas y seculares la religión se aparta completamente de lo público, aunque ciertas instituciones religiosas sí sean apartadas. Gracias a la antropología también se sabe que para muchos grupos humanos la religión no 
es una especie de opción personal de creer o no creer, una operación mental optativa que no modifica esencialmente la forma de vivir, sino que la religión es un sistema cultural (Geertz, 2001) y, como tal, no se puede separar de lo social, con todo lo que este término implica; asimismo, si la religión es un «modo de existencia» (Latour, 2013), ella se construye y, sobre todo, se vive en sociedad.

Si bien es cierto que en nuestra modernidad el sujeto tendría la opción de creer o no creer (Luhrmann, 2012, p. 378), lo cual obedece a un proceso de desinstitucionalización e individualización de la experiencia religiosa (Beck, 2009; Sarrazin, 2017), es clave tener en cuenta que, aun en los casos de una espiritualidad aparentemente autónoma, las decisiones individuales se toman en función de marcos referenciales que son construcciones sociohistóricas (Aupers y Houtman, 2010, p. 139; Wood, 2007, p. 29). Concebir la religión como una cuestión meramente personal niega u ocluye la importancia de sus orígenes y consecuencias sociales.

La modernidad liberal implica un proceso de individualización generalizado. Este proceso significa que el sujeto puede y debe buscar su propia identidad, sus propias creencias, sus propios valores, así como sus [ 84 ] propios deseos (Arnal, 2001; Beck, 2009). El liberalismo se basa en un elogio de la libertad para elegir. En palabras de Gilles Lipovetsky (1989, p. 58), estamos en una época de «sistemas a la carta», donde el individuo debe liberarse de la influencia del Otro. El sujeto moderno y «emancipado» es el primero en la historia de la humanidad que pretende construir sus creencias independientemente de la sociedad en la que vive (Gauchet, 2002, pp. 229-262).

Lo anterior es clave en términos políticos, ya que constituye el fundamento ideológico que permitiría que las comunidades religiosas o las Iglesias - en tanto que organizaciones donde se buscan cambios colectivos de creencias, valores, deseos y comportamientos- sean vistas con recelo. Así, esos símbolos por excelencia de la «religión» que son las Iglesias pueden ser percibidas como instituciones antiliberales y son susceptibles de ser calificadas como formas de «fanatismo» o «fundamentalismo» (Arnal, 2001). Efectivamente, la construcción comunitaria de motivaciones no corresponde con el sistema cultural hegemónico basado en el individualismo (Arnal y McCutcheon, 2013). 


\section{La religión como creencias en lo sobrenatural}

Para la escuela evolucionista del siglo xIx, representada en obras como las de Edward Tylor (1981) o James Frazer (2011), la religión proviene de la creencia del «hombre primitivo» en agentes o poderes sobrenaturales o espirituales que causan los fenómenos naturales. En ese sentido, la religión siempre es una forma de conocimiento inferior a la ciencia moderna, ya que se basa en creencias erradas acerca de las relaciones de causalidad en el mundo. No obstante, para proponer estos supuestos fundamentos de las religiones humanas en general, ninguno de los dos autores mencionados tuvo suficientes evidencias empíricas porque nunca conocieron suficientemente a las sociedades de las que estaban hablando (Bowie, 2006, p. 8).

A pesar de las críticas, esa concepción de la religión aún sigue vigente en ciertos medios académicos e institucionales. En Colombia, por ejemplo, las definiciones oficiales incluyen la presencia de una «divinidad», es decir, un ser o fuerza sobrenatural. Por su parte, citando solo algunos ejemplos de este tipo de definiciones desde la academia, para William Bainbridge (2005) «la religión se refiere a sistemas de compensadores generales basados en suposiciones sobrenaturales» (p. 5); Markus Davidsen (2014), por su parte, define la religión como «creencias, prácticas, experiencias y discursos que asumen la existencia de agentes, mundos y/o procesos sobrenaturales» (p. 31); Rodney Stark y Roger Finke (2000) entienden la religión desde una racionalidad económica y consideran que el éxito de las religiones se basa en reproducir la esperanza de obtener beneficios gracias a seres o poderes sobrenaturales; en esa misma vena se encuentra la obra del célebre filósofo anglosajón Daniel Dennett (2007), para quien «el fenómeno central de la religión invoca dioses que son agentes efectivos en tiempo real, y que juegan [sic] un rol central en la manera en que los participantes piensan acerca de lo que deben hacer» (p. 30). Estas perspectivas no consideran, sin embargo, que la importancia del concepto de dios o de una divinidad cualquiera, más allá de ser un agente sobrenatural al que se le piden cosas o que actúa sobre el mundo material, podría ser un símbolo central en un sistema de creencias más complejo.

Las teorías que ponen en el centro de la religiosidad la creencia en divinidades o seres sobrenaturales contribuyen a reforzar la idea de que los grupos considerados como «religiosos» se fijan en temas que no tienen ninguna consecuencia en el mundo material o en las realidades sociales, económicas 
y políticas. No es casual que esta categorización también haya sido puesta en práctica para menospreciar las formas culturales de las poblaciones colonizadas por las potencias europeas. Se observó en un apartado anterior un caso en el que la Corte Constitucional de Colombia categoriza como «comunidad religiosa» a un grupo étnico, asumiendo que los indígenas son pueblos profundamente espirituales, suposición que, a su vez, se basó — como suele ocurrir- en los conceptos de «expertos» en ciencias sociales (Sarrazin y Redondo, 2018). Clasificar a los indígenas como pueblos «espirituales», aunque en principio parezca un favor para ellos, también implica su inferiorización respecto a los sistemas de conocimiento «racionales» propios de la cultura secular, sistemas que serían los verdaderamente aptos para tomar las decisiones políticas más importantes. Así, el concepto de religión permite desprestigiar las prácticas que puedan interferir con los intereses de los grupos dominantes (Fitzgerald, 2007, p. 41).

Por otro lado, concebir la religión como un conjunto de creencias en seres o poderes sobrenaturales implica un dualismo natural-sobrenatural que, lejos de ser propio de aquellos grupos considerados como profundamente espirituales, es en realidad una invención de la modernidad occidental (Latour, 2013). Este dualismo es paralelo a la división entre entidades reales o imaginarias. Los modernos se ocuparían de lo real, los religiosos de lo imaginario, verbigracia, las divinidades. Pero este dualismo impide comprender que para muchas personas no tiene sentido preguntarse si dios es real o no, y no porque para ellos dios sí sea real, sino porque no da cuenta de la manera en que esas personas entienden un concepto que no es sometido a la dicotomía real-imaginario (Harries, 2016). Por demás, esto impediría comprender la manera en que aquellas personas entienden el mundo en general, puesto que el concepto de dios permearía toda su ontología.

Asociar el concepto de dios con la categoría de seres sobrenaturales que inciden en el mundo natural — causando «milagros», por ejemplo— es limitar su comprensión a una categoría moderna. Así como para algunas sociedades no hay separación entre lo natural y lo sobrenatural, ciertos grupos religiosos en Occidente (Luhrmann, 1989, p. 274) pueden hablar de un «plano mágico» que no afecta en absoluto la materialidad de sus entornos. En ese tipo de casos no hay verificación empírica posible y no tiene sentido intentar plantearla. El lenguaje religioso aparentemente no puede ser leído bajo el mismo código que el lenguaje científico; en cambio, quizás el primero pueda ser relativamente cercano al lenguaje de la literatura y la poesía. Respecto a este 
último caso, parecería absurdo someter a evaluación científica y verificación empírica frases poéticas como «vuelo cuando oigo tu voz» o «tus ojos son dos luceros». Evidentemente no hay tal acto de volar y es imposible que una persona tenga luceros en la cara. No se trata de enunciados científicamente verificables. ¿Se trata entonces de afirmaciones sobre seres sobrenaturales que vuelan o tienen rostros imposibles? Cualquiera que conoce de literatura sabe que no. Quien escribe poesía no es una persona que cree —erradamenteque hay seres sobrenaturales que, aunque nunca vistos, realmente existen en alguna parte. Asimismo, Latour (2005) invita a dejar de lado la tendencia a juzgar las afirmaciones llamadas «religiosas» desde el marco referencial de la racionalidad científica. Después de todo, el lenguaje religioso puede estar como la poesía — repleto de símbolos y metáforas.

Todos los lenguajes requieren de un proceso de interpretación particular y todos pueden cumplir objetivos diferentes. El objetivo de las afirmaciones religiosas quizás no sea el de describir el mundo natural ni el sobrenatural, sino el de lograr un efecto en las personas. Según Latour (2005), las religiones —al menos algunas de ellas - plantean mensajes cuyo objetivo no es transmitir información, sino transformar personas. En el mismo sentido, agrega el autor, las imágenes religiosas no tienen el objetivo de representar algo que está «allá afuera» o «más allá», sino que tienen el efecto de volver a hacer presente re-presentar, en un sentido particular de la palabra- una experiencia en el sujeto. Las palabras, los símbolos, traen a la mente a esos «seres» que tienen un efecto en las personas. Así pues, recalca Latour, la «verdad» del religioso depende de haber logrado tal efecto, no de representar correctamente los objetos. Las palabras «especiales» que contiene la poesía o el lenguaje religioso son «portadoras de seres capaces de renovar a aquellos a quienes se dirigen» (Latour, 2013, p. 294). Los aportes de Latour se basan seguramente en el trabajo de Claude Lévi-Strauss (1995, p. 211), que nos enseñó que los seres imaginarios de los que hablan los mitos de diferentes sociedades tienen una «eficacia simbólica». Esos seres son símbolos y los símbolos tienen efecto sobre las personas, son agentes con la capacidad de actuar sobre las estructuras mentales de los humanos que los perciben e interpretan de determinadas maneras.

La capacidad transformadora y movilizadora de los símbolos es un factor evidentemente político; sin embargo, persistir en hablar de las religiones como creencias en lo sobrenatural permite descalificarlas y excluir 
a las comunidades religiosas del debate político y las decisiones prácticas de la vida social. Incluso permite que se reproduzca el discurso - que a veces recuerda la frase «el opio del pueblo»— sobre la religión como una forma de conocimiento que mantiene al pueblo ignorante y oprimido. Quizás la Iglesia católica u otras Iglesias puedan ser acusadas de ser esa religión; no obstante, al presumir que todo lo clasificado como «religión» es un conjunto de creencias falsas se deslegitiman las propuestas morales, ontológicas o políticas de los grupos «religiosos». Por oposición, quienes se autodefinen como no religiosos y racionales se ubican en un lugar superior de la jerarquía social, con mayor autoridad para decidir lo que se debe hacer colectivamente.

Lo anterior no implica solamente que los grupos tradicionalmente llamados «religiosos» sean excluidos del debate político, también sucede que las agendas políticas y sociales que realmente contradicen la hegemonía cultural de la modernidad liberal están siendo categorizadas en diferentes países del mundo como «religiosas», un acto clasificatorio que las excluye (Arnal y McCutcheon, 2013).

\section{Conclusión}

[ 88 ] Aunque desde ciertos sectores de la academia y la institucionalidad se asume que la religión es una categoría universal, este estudio permite notar que la imposición del término sobre ciertas expresiones culturales o grupos humanos es un acto clasificatorio que corresponde a un marco interpretativo particular, fruto de la historia, y no puede desligarse de un marco de relaciones de poder. Lo religioso y lo secular no son esencias inmutables o ideologías opuestas, sino conceptos que fueron ganando cada vez más relevancia en las políticas modernas.

El uso de la categoría de «religión» para definir y entender la diversidad cultural puede convertirse en un dispositivo que busca hacer coincidir a la fuerza ciertos fenómenos socioculturales dentro de los marcos conceptuales modernos: una suerte de colonialismo conceptual. Si no existe consenso respecto a lo que es la religión y se reconoce la dificultad o imposibilidad de trazar analíticamente los límites de lo religioso en la complejidad de fenómenos socioculturales de cualquier sociedad, es entonces necesario preguntarse si es científicamente viable y pertinente identificar ciertas propuestas políticas bajo las categorías de lo religioso o lo secular. 
En el momento en que ciertas cosmovisiones, ontologías, ideologías o modos de existencia son clasificados como «religiosos» surge la posibilidad de que sean asociados a una serie de presupuestos etnocéntricos. Lo anterior no sería relevante más allá de la lingüística, si no fuera porque los efectos políticos de ese acto clasificatorio son considerables y, generalmente, desfavorables para los grupos sociales que son así clasificados. En efecto, los argumentos y las propuestas de un grupo «religioso» gozan de poca legitimidad en los debates que afectan a la mayoría de la población.

Esto parecería incoherente con los principios pluralistas de democracias como la colombiana. Se acepta y reconoce la diversidad religiosa, pero, paradójicamente, el solo hecho de caer en la categoría de religión representa un punto de partida desventajoso. El pluralismo parece aceptar las religiones en cuanto se mantengan como creencias privadas o correspondan con ciertos esquemas propios de la cristiandad. Al proponer modos de existencia verdaderamente alternativos y reclamar su espacio en lo público, las religiones se convierten en problemáticos interlocutores. En ese momento son asociadas a Iglesias que se opondrían al valor de la libertad individual imponiendo — como si fueran las únicas que lo hacen— un esquema de pensamiento, unos valores, una identidad, unas motivaciones. Fácilmente son entonces censuradas como fanatismos o fundamentalismos incompatibles con la modernidad liberal.

Por otro lado, cuando se asume que se trata de creencias en seres o poderes sobrenaturales, se refuerza la idea de que se trata de un pensamiento irracional e infundado, irrelevante para tomar decisiones que conciernen el mundo real. La religión se equipara a la fantasía, la ficción o las explicaciones falsas, por lo cual su aporte a la sociedad sería equivocado o inconsecuente. Mediante este tipo de presupuestos presentes en las definiciones de religión, los proyectos clasificados como «religiosos»son, por así decirlo, excluidos del este mundo y, por consiguiente, de la esfera pública.

\section{Referencias bibliográficas}

1. Arnal, William. (2001). The Segregation of Social Desire. «Religion» and Disney World. Journal of the American Academy of Religion, 69 (1), pp. 1-19. https://doi. org/10.1093/jaarel/69.1.1

2. Arnal, William \& McCutcheon, Russell. (2013). The Sacred is the Profane. The Political Nature of «Religion». New York: Oxford University. https://doi.org/10.1093/ acprof:oso/9780199757114.001.0001 
3. Asad, Talal. (1993). Genealogies of Religion. Discipline and Reasons of Power in Christianity and Islam. Baltimore: Johns Hopkins University.

4. Aupers, Stef \& Houtman, Dick. (2010). The Social and Public Significance of New Age Spirituality. In: Aupers, Stef \& Houtman, Dick (Eds.). Religions of Modernity: Relocating the Sacred to the Self and the Digital (pp. 135-160). Leiden: Brill Academic.

5. Bainbridge, William. (2005). Atheism. Interdisciplinary Journal of Research on Religion, 1 (1), pp. 1-23.

6. Bastian, Jean-Pierre. (2007). Pluralización religiosa, laicidad del Estado y proceso democrático en América Latina. Historia y Grafía, 29, pp. 167-194.

7. Beaman, Lori. (2013). Battles over Symbols: The «Religion» of the Minority Versus the "culture» of the Majority. Journal of Law and Religion, 28 (1), pp. 67-104. https://doi.org/10.1017/S0748081400000242

8. Beck, Ulrich. (2009). El Dios personal. La individualización de la religión y el «espíritu» del cosmopolitismo. Barcelona: Paidós.

9. Beckford, James. (2003). Social Theory and Religion. Cambridge: Cambridge University. https://doi.org/10.1017/CBO9780511520754

10. Bellah, Robert. (1967). Civil Religion in America. Daedalus, 96 (1), pp. 1-21.

11. Beltrán, William. (2013). Pluralización religiosa y cambio social en Colombia. Theologica Xaveriana, 63 (175), pp. 57-85.

12. Benthall, Jonathan. (2008). Returning to Religion: Why a Secular Age is Haunted by Faith. London: I. B. Tauris. https://doi.org/10.5040/9780755625062

13. Berger Peter. (1974). Some Second Thoughts on Substantive Versus Functionalist Definitions of Religion. Journal for the Scientific Study of Religion, 13 (2), pp. 125-133. https://doi.org/10.2307/1384374

14. Berger, Peter (Ed.). (1999). The Desecularization of the World: Resurgent Religion and World Politics. Washington: Ethics and Public Policy Center.

15. Beyer, Peter. (1999). Religión, problemas residuales y diferenciación funcional: una relación ambigua. Sociológica, 14 (41), pp. 199-209.

16. Beyer, Peter. (2013). Questioning the Secular/Religious Divide in a Post-Westphalian World. International Sociology, 28 (6), pp. 663-679. doi: 10.1177/0268580913507070

16. Bobbio, Norberto. (2005). Cultura laica y laicismo. Iglesia Viva, 222, pp. 147-149.

17. Bowie, Fiona. (2006). Anthropology of Religion. In: Segal, Robert Alan (Ed.). The Blackwell Companion to the Study of Religion (pp. 3-24). Malden: Blackwell. https://doi.org/10.1111/b.9780631232162.2006.00003.x

18. Casanova, José. (1994). Public Religions in the Modern World. Chicago: University of Chicago. https://doi.org/10.7208/chicago/9780226190204.001.0001

19. Casanova, José. (2009). The Secular and Secularisms. Social Research, 76 (4), pp. 1049-1066. 
20. Colombia. Asamblea Nacional Constituyente. Constitución Política de la República de Colombia. (20 de julio de 1991). http://www.secretariasenado.gov.co/ senado/basedoc/constitucion_politica_1991.html

21. Colombia. Corte Constitucional. Sentencia C-088. (3 de marzo de 1994). https://www.corteconstitucional.gov.co/relatoria/1994/c-088-94.htm

22. Colombia. Corte Constitucional. Sentencia SU-510. (18 de septiembre de 1998). http://www.corteconstitucional.gov.co/relatoria/1998/SU510-98.htm

23. Colombia. Corte Constitucional. Sentencia T-662. (7 de septiembre de 1999). https://www.corteconstitucional.gov.co/relatoria/1999/T-662-99.htm

24. Davidsen, Markus. (2014). The Spiritual Tolkien Milieu. A Study of Fiction! based Religion. (PhD. Thesis in Philosophy). Universidad de Leiden, Leiden.

25. Davie, Grace. (1990). Believing without Belonging: Is This the Future of Religion in Britain? Social Compass, 37 (4), pp. 455-469. https://doi. org/10.1177/003776890037004004

26. Debray, Regis. (2005). Les communions humaines. Pour en finir avec la «religión». Paris: Fayard.

27. Derrida, Jacques. (1996). Post-scriptum. En: Derrida, Jacques y Vattimo, Gianni (eds.). La religión (pp. 37-106). Madrid: PPC.

28. Durkheim, Émile. (1898). De la définition des phénomènes religieux. Année Sociologique. 2, pp. 1-28.

29. Durkheim, Émile. (1982). Las formas elementales de la vida religiosa. Madrid: Akal.

30. Dennett, Daniel. (2007). Romper el hechizo: la religión como fenómeno natural. Buenos Aires: Katz. https://doi.org/10.2307/j.ctvm7bf9d

31. De La Torre, Renée. (2012). Religiosidades nómadas. Guadalajara: CIESAS.

32. Evans-Pritchard, Edward. (1973). Las teorías de la religión primitiva. Madrid: Siglo XXI.

33. Fitzgerald, Timothy. (2007). Encompassing Religion, Privatized Religions, and the Invention of Modern Politics. In: Fitzgerald, Timothy (Ed.). Religion and the Secular: Historical and Colonial Formations (pp. 211-240). London: Equinox.

34. Frazer, James. (2011). La rama dorada. México, D. F.: Fondo de Cultura Económica.

35. Gauchet, Marcel. (2002). La Democratie contre Elle-Même. Paris: Gallimard.

36. Geertz, Clifford. (2001). La interpretación de las culturas. Barcelona: Gedisa.

37. Godoy, María Jesús. (2016). La condición sacra del desacralizado arte contemporáneo. Aisthesis, 59, pp. 203-222. https://doi.org/10.4067/S071871812016000100012

38. Habermas, Jürgen. (2005). Equal Treatment of Cultures and the Limits of Postmodern Liberalism. Journal of Political Philosophy, 13 (1), pp. 1-28. https://doi. org/10.1111/j.1467-9760.2005.00211.x 
39. Habermas, Jürgen. (2006). Religion in the Public Sphere. European Journal of Philosophy, 14 (1), pp. 1-25. doi: 10.1111/j.1468-0378.2006.00241.x

40. Habermas, Jürgen. (2010). An Awareness of What is Missing: Faith and Reason in a Post-Secular Age. Cambridge: Cambridge Polity.

41. Harries, Jim. (2016). The Godless Delusion: Europe and Africa. Eugene: Wipf and Stock.

42. James, William. (1986). Las variedades de la experiencia religiosa: estudio de la naturaleza humana. Barcelona: Península.

43. Latour, Bruno. (2005). "Thou Shall Not Freeze-Frame» - or How not to Misunderstand the Science and Religion Debate. In: Proctor, James (Ed.). Science, Religion, and the Human Experience (pp.27-48). Oxford: Oxford University. https:// doi.org/10.1093/0195175328.003.0003

44. Latour, Bruno. (2013). Investigación sobre los modos de existencia. Una antropología de los modernos. Buenos Aires: Paidós.

45. Lévi-Strauss, Claude. (1995). Antropología estructural ı. Buenos Aires: Paidós.

46. Lipovetsky, Gilles. (1989). La era del vacío. Barcelona: Anagrama.

47. Luckmann, Thomas. (1973). La religión invisible. Salamanca: Sígueme.

48. Luhrmann, Tanya. (1989). Persuasions of the Witch's Craft: Ritual Magic in Contemporary England. Cambridge: Harvard University.

49. Luhrmann, Tanya. (2012). A Hyperrealgod and Modern Belief. Toward an Anthropological Theory of Mind. Current Anthropology, 53 (4), pp. 371-395. https://

[ 92 ] doi.org/10.1086/666529

50. Nongbri, Brent. (2013). Before Religion: A History of a Modern Concept. New Haven: Yale University. https://doi.org/10.12987/yale/9780300154160.001.0001

51. Mallimaci, Fortunato y Esquivel, Juan. (2014). La contribución de la política y el Estado en la construcción del poder religioso. Revista Argentina de Ciencia Política, 17, pp. 71-89.

52. Mardones, José María. (2006). Religión y democracia. Cuestiones Teológicas, 33 (79), pp. 9-26.

53. Masuzawa, Tomoko. (2005). The Invention of World Religions. Chicago: The University of Chicago. https://doi.org/10.7208/chicago/9780226922621.001.0001

54. Meyer, Birgit. (2015). Picturing the Invisible. Visual Culture and the Study of Religion. Method and Theory in the Study of Religion, 27, pp. 333-360. https://doi. org/10.1163/15700682-12341357

55. Otto, Rudolf. (2005). The Idea of the Holy. In: McCutcheon, Russell (Ed.). The Insider/Outsider Problem in the Study of Religion: A Reader (pp. 74-81). New York: Continuum.

56. Parker, Cristián. (2005). ¿América Latina ya no es católica? Pluralismo cultural y religioso creciente. América Latina Hoy, 41, pp. 35-56. https://doi.org/10.14201/ alh. 2431 
57. Parker, Cristián. (2010). El eclesiocentrismo en los clásicos de la sociología occidental. En: Gutiérrez, Daniel (ed.). Religiosidades y creencias contemporáneas. Diversidad de lo simbólico en el mundo actual (pp. 47-69). Zinacantepec: El Colegio Mexiquense.

58. Sarrazin, Jean Paul. (2017). Budismo universal, budismo individual. Análisis del interés por la espiritualidad oriental en Occidente. Revista Escritos, 25 (54), pp. 59-81. https://doi.org/10.18566/escr.v25n54.a04

59. Sarrazin, Jean Paul. (2018). Religión: ¿sabemos de lo que estamos hablando? Examen sobre la viabilidad de una categoría analítica para las ciencias sociales. Criterio Libre, 16 (29), pp. 68-84. https://doi.org/10.18041/1900-0642/ criteriolibre.2018v16n29.5008

60. Sarrazin, Jean Paul y Arango, Paulina. (2017). La alternativa cristiana en la modernidad tardía. Razones de la migración religiosa del catolicismoal pentecostalismo. Revista Folios, 46, pp. 41-54. doi: 10.17227/01234870.46folios41.54

61. Sarrazin, Jean Paul y Redondo, Saira Pilar. (2018). Indígenas evangélicos y diversidad cultural. Análisis de una problemática multiculturalista. Revista de Derecho, 49, pp. 203-228.

62. Sarrazin, Jean Paul y Rincón, Lina. (2015). La conversión al islam como estrategia de cambio y diferenciación en la modernidad. Revista de Estudios Sociales, 51, pp. 132-145. doi: 10.7440/res51.2015.10

63. Smart, Ninian. (2005). Within and Without Religion. In: McCutcheon, Russell (Ed.). The Insider/Outsider Problem in the Study of Religion (pp. 221-234). New York: Continuum.

64. Smith, Jonathan. (1982). Imagining Religion. From Babylon to Jonestown. Chicago: Chicago University.

65. Smith, Jonathan. (1998). Religion, Religions, Religious. In: Taylor, Mark (Ed.). Critical Terms for Religious Studies (pp. 269-84). Chicago: University of Chicago.

66. Stark, Rodney \& Finke, Roger. (2000). Acts of Faith: Explaining the Human Side of Religion. Berkeley: University of California. https://doi.org/10.1525/9780520924345

67. Schmitt, Carl. (2000). Catolicismo y forma política. Madrid: Tecnos.

68. Taylor, Charles. (2007). A Secular Age. Cambridge: Harvard University. https://doi.org/10.2307/j.ctvxrpz54

69. Tylor, Edward. (1981). Cultura primitiva II. La religión en la cultura primitiva. Madrid: Ayuso.

70. United Kingdom. The Supreme Court. Judgment UKSC 77. (11 December 2013). R (on the application of Hodkin and another) (Appellants) v Registrar General of Births, Deaths and Marriages (Respondent). https:/www.supremecourt.uk/cases/ docs/uksc-2013-0030-judgment.pdf

71. Wood, Matthew. (2007). Possession, Power, and the New Age: Ambiguities of Authority in Neoliberal Societies. Aldershot: Ashgate. 